\title{
Article \\ The Effect of Mass Transfer Rate-Time in Bubbles on Removal of Azoxystrobin in Water by Micro-Sized Jet Array Discharge
}

\author{
Feng Chen ${ }^{1,2}$, Dezheng Yang ${ }^{2,3}$, Feng Yu ${ }^{1} \mathbb{C}$, Yang Kun ${ }^{3, *}$ and Ying Song ${ }^{2,4, *}$ \\ 1 Key Laboratory for Green Processing of Chemical Engineering of Xinjiang Bingtuan, School of Chemistry and \\ Chemical Engineering, Shihezi University, Shihezi 832003, China; fallenmaple@foxmail.com (F.C.); \\ yufeng05@mail.ipc.ac.cn (F.Y.) \\ 2 Key Lab of Materials Modification, Ministry of Education, Dalian University of Technology, \\ Dalian 116024, China; yangdz@dlut.edu.cn \\ 3 Key Laboratory of Ecophysics, College of Sciences, Shihezi University, Shihezi 832003, China \\ 4 School of Physics and Materials Engineering, Dalian Minzu University, Dalian 116600, China \\ * Correspondence: yangk_shz@sina.com (Y.K.); songying@dlnu.edu.cn (Y.S.)
}

Citation: Chen, F.; Yang, D.; Yu, F.; Kun, Y.; Song, Y. The Effect of Mass Transfer Rate-Time in Bubbles on Removal of Azoxystrobin in Water by Micro-Sized Jet Array Discharge. Catalysts 2021, 11, 1169. https:// doi.org/10.3390/catal11101169

Academic Editor: Albin Pintar

Received: 4 August 2021

Accepted: 17 September 2021

Published: 27 September 2021

Publisher's Note: MDPI stays neutral with regard to jurisdictional claims in published maps and institutional affiliations.

Copyright: (c) 2021 by the authors. Licensee MDPI, Basel, Switzerland. This article is an open access article distributed under the terms and conditions of the Creative Commons Attribution (CC BY) license (https:// creativecommons.org/licenses/by/ $4.0 /)$.

\begin{abstract}
In this work, the azoxystrobin removal in water by using a micro-size discharge array was investigated, and the removal efficiency can reach as high as $98.1 \%$ after $9 \mathrm{~min}$ plasma treatment as well as the energy utilization being only $0.73 \mathrm{~g} /(\mathrm{kW} \cdot \mathrm{h})$. Based on the relationship between the generation of gas bubbles and parameters of gas-liquid discharge, it was found that the variation of applied voltage, gas flow rate and initial solution temperature could cause particle number change, mass transfer rate change and the mass transfer time change, which significantly affected the practical applications at last. The experimental results indicated that when gas flow rate was 0.7 SLM (Standard Liter per Minute) and the initial solution temperature was $297 \mathrm{~K}$ with the applied voltage of $8 \mathrm{kV}$ and discharge frequency of $6 \mathrm{kHz}$, the removal efficiency of azoxystrobin achieved maximum. Based on the analysis results of liquid mass spectrometry, the removal pathways of azoxystrobin were supposed by the decomposed by-products. Toxicity tests indicated that the decomposed products were safe and non-toxic. So, this study may reveal an azoxystrobin degradation mechanism and provide a safe, reliable and effective way for azoxystrobin degradation.
\end{abstract}

Keywords: non-thermal plasma; azoxystrobin; micro-discharge array reactor; mass transfer; degradation

\section{Introduction}

In the preceding century, agricultural intensification supported by the use of pesticides increased human food supply to satisfy the rapidly increasing population demands on earth [1]. While intensive agriculture enhanced the output of agricultural products, it also caused serious toxic pesticide residue in environmental matrices [2,3]. Combined with climate change, these residual pesticides might easily dissolve in the water or bind to suspended matter in the aquatic environment.

As a highly effective systemic and broad-spectrum fungicide, azoxystrobin occupies a large portion of the market share [4]. The melting point and boiling point of azoxystrobin are $389 \mathrm{~K}$ and $618 \mathrm{~K}$, respectively. It can be decomposed by sunlight and UV light with a half-life of 11 days. So, the physical properties of azoxystrobin are stable [5] and the azoxystrobin is indispensable for modern agriculture. Due to widespread application of azoxystrobin, the azoxystrobin residual has been detected in many waters and crops and the residual concentration can reach as high as 6 ppm [6,7]. Recent studies showed that azoxystrobin residual eventually transferred to the non-target organisms' tissues during bioaccumulation processes [8,9], resulting in adverse effects on diverse ecosystems, including aquatic habitat loss [10] and fishery economic loss [11], as well as human health risks [12]. Therefore, azoxystrobin residue problem has caused worldwide public concern. 
Various methods, such as ozonation [13,14], photocatalysis $[15,16]$ and electrooxidation $[17,18]$, have been tested for hazardous contaminant reduction in the environment. The removal efficiency of these advanced oxidation technologies is high. However, chemical reagent overuse can also cause secondary pollution. As one of the emerging advanced oxidation processes, non-thermal plasma (NTP) is generated by gas-liquid discharge using air as working gas and can produce reactive species with strong chemical activity, such as $\mathrm{OH}, \mathrm{O}$ and $\mathrm{N}_{2}{ }^{+}$. These reactive species can react with targets and form water, oxygen and nitrogen, which are environmentally friendly. Due to these unique characteristics, it has attracted great attention. The studies reported by Zong et al. showed that the degradation rate of omethoate by using atmospheric pressure surface discharges could achieve $99 \%$ and pointed out that the reactive oxygen species were crucial in the degradation process [19]. Magureanu et al. reported an investigation on degradation of cefixime antibiotic in water by gas-liquid discharge and the final organic by-products presented in the solution were divided into mainly small non-toxic molecules [20]. In the gas-liquid discharge, the interactions between plasma and aqueous solution contain complex chemical processes under the coupling of multiple physical fields. On one hand, it contains interactions between coupling of multiple physical fields (such as electromagnetic field, local thermal field, density field and airflow field) and an aqueous solution which can generate a series of physical phenomenon, such as droplet splashing, Taylor cone, interface turbulence and shock wave [21]. On the other hand, the active species generated by gasliquid discharge transfer into aqueous solution under the effects of multiple physical fields and react with water molecules, organic solutes and inorganic solutes through complex chemical reactions. The reactions conclude photoionization, ion transfer, penning ionization, hydrolysis and electrolysis [22]. These physical and chemical processes are intense in the thin layers of the gas-liquid interface. The active species generated by discharge in gas phase need to transfer through gas-liquid interface layer to act on the treated objects in aqueous solution. The existence of aqueous solution weakens the physical action of this NTP and changes the effective chemical composition of NTP, which ultimately affects the practical application effects [23]. Previous researches indicate that active species include excited state particles, ultraviolet photons and free radicals, as well as play the critical role in practical applications $[24,25]$. Due to the chemical reactions mainly happening in the gas-liquid interface layer, the reactive species mass transfer processes are very important.

In this study, we designed a type of micro-size discharge array for azoxystrobin degradation. Due to the micro-sized discharge unit configuration, the contact area between gas-phase and liquid-phase efficiently increased, which facilitated the mass transfer rate of reactive species. In addition, micro-sized discharge array divided the large-scale discharge region into many micro-discharge regions, which greatly improved the stability of discharge and reduced energy consumption [26,27]. For applying gas-liquid plasma to wastewater purification, many investigations found that the mass transfer processes of reactive species played a critical role in the whole degradation processes [28,29]. However, there was still a lot of work to do, such as the relationship between mass transfer processes and removal efficiency. So, in this paper, we attempted, (1) to find out the optimal NTP treatment parameters of azoxystrobin degradation, (2) to obtain the relationship of mass transfer of reactive species in the degradation processes and (3) to conclude the degradation pathways of azoxystrobin treated by NTP.

\section{Materials and Methods}

\subsection{Chemicals and Instruments}

Azoxystrobin (purity $>99 \%$ ) was purchased from Shanghai Aladdin Bio-Chem Technology Co., Ltd., Shanghai, China, dissolved in deionized water and sonicated for $2 \mathrm{~min}$ in the dark to prepare the azoxystrobin stock solution. Acetonitrile (chromatographically pure) was also obtained from Shanghai Aladdin Bio-Chem Technology Co., Ltd., China, as mobile phase of LC (Liquid Chromatogram) system. 


\subsection{Plasma Reactor}

The schematic of organic wastewater treatment system was illustrated in Figure 1a. It was mainly composed of micro-plasma jet array, gas input system, AC power supply (CTP 2000K, Nanjing Suman Electronics, Nanjing, China) and detection and analysis system. The plasma jet array device mainly consisted of 15 plasma jets equilaterally distributed in a quartz container as shown in Figure 1b. Different to traditional millimeter-sized jet configuration, here, we used micron quartz capillaries as dielectric tube. The inner and outer diameter of hollow quartz capillaries were $400 \mu \mathrm{m}$ and $800 \mu \mathrm{m}$, respectively. Tungsten wires ( $200 \mu \mathrm{m}$ in diameter) connected with AC power supply were inserted into the capillaries, acting as the high-voltage electrode; $40 \mathrm{~mL}$ aqueous solutions containing azoxystrobin with the concentration of $6 \mathrm{mg} / \mathrm{L}$ were added into the quartz container and connects with the ground acting as the ground electrode. Air gas, which was controlled by mass flow controller (D08-4E, Sevenstar, Beijing, China), with the flow rate varying from 0.7 to 5.0 SLM (Standard Liter per Minute), flowed from these hollow quartz capillaries into the aqueous solution. The AC power supply was capable to generate the peak to peak voltage $\left(\mathrm{V}_{\mathrm{p}-\mathrm{p}}\right)$ in the range of $0-15 \mathrm{kV}$ at the frequency of $6 \mathrm{kHz}$. Discharge current and voltage were obtained by using a digital oscilloscope (MSO56, Tektronix, Beaverton, OR, USA) with a current probe (Pearson 4100, Palo Alto, CA, USA) and a high-voltage probe (P6015A, Tektronix, Beaverton, OR, USA). When the AC high-voltage was applied on the tungsten wires, the discharge was produced in the space between the tungsten and the air bubble.
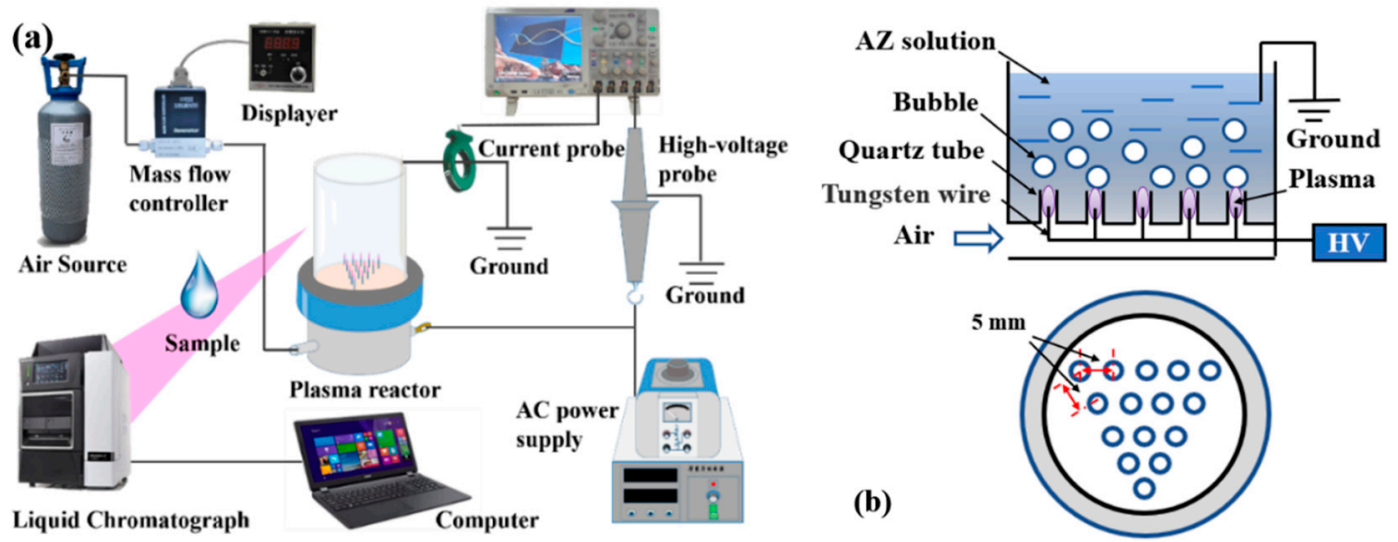

Figure 1. (a) Schematic diagram of the organic wastewater treatment system; (b) The structure of micro-discharge array device.

\subsection{Experimental Procedure}

As a model pollutant, the azoxystrobin solution was prepared by dissolving $6 \mathrm{mg}$ azoxystrobin powders into $1 \mathrm{~L}$ ultrapure water. Due to the relatively low solubility of azoxystrobin powder $(6.7 \mathrm{mg} / \mathrm{L}, 297 \mathrm{~K})$ [30], the azoxystrobin solution was sonicated by using an ultrasonic cleaning machine (f-020s, Fuyang, China) for 2 min in the dark to ensure the solute completely dissolved. Then, $40 \mathrm{~mL}$ of prepared azoxystrobin solution was spiked into the container as the treated sample. The treatment time varied from 1 to 9 min with $V_{p-p}$ in the range of 6-10 kV, and in each of the experimental conditions, $1 \mathrm{~mL}$ of treated solution was obtained by the pipettor and filtered with $0.45 \mu \mathrm{m} \mathrm{MCM}$ syringe filters for LC analysis. All the experimental results were an average of 3 parallel repeated trials.

\subsection{Analytical Methods}

The concentration of azoxystrobin solution treated by plasma was measured by a LC system (Shimadzu, LC-2030, Kyoto, Japan) equipped with an AQ-C18 column $(\varnothing 4.6 \mathrm{~mm} \times 250 \mathrm{~mm})$ and an ultraviolet-visible detector with the wavelength set at $255 \mathrm{~nm}$. The working conditions of HPLC were as following: column temperature set as $26^{\circ} \mathrm{C}$, flow rate set as $1 \mathrm{~mL} / \mathrm{min}$ and injection volume set as $50 \mu \mathrm{L}$. The mobile phase was prepared 
with chromatographically-pure acetonitrile and ultra-pure water. Gradient elution method was used during the detection process. In detail, from 0 to $5 \mathrm{~min}$, the proportion of water was $37.5 \%$; from 5 to $11 \mathrm{~min}$, the proportion of water was $20 \%$.

The removal efficiency $(\eta)$ of azoxystrobin is defined as Equation (1):

$$
\eta=\frac{C_{0}-C_{t}}{C_{0}} \times 100 \%
$$

where $C_{0}$ was the concentration of azoxystrobin solution and $C_{t}$ was the concentration of treated azoxystrobin solution. Both $C_{0}$ and $C_{t}$ were calculated from the peak area of recommended chromatographic fingerprints as shown in Figure 2a.
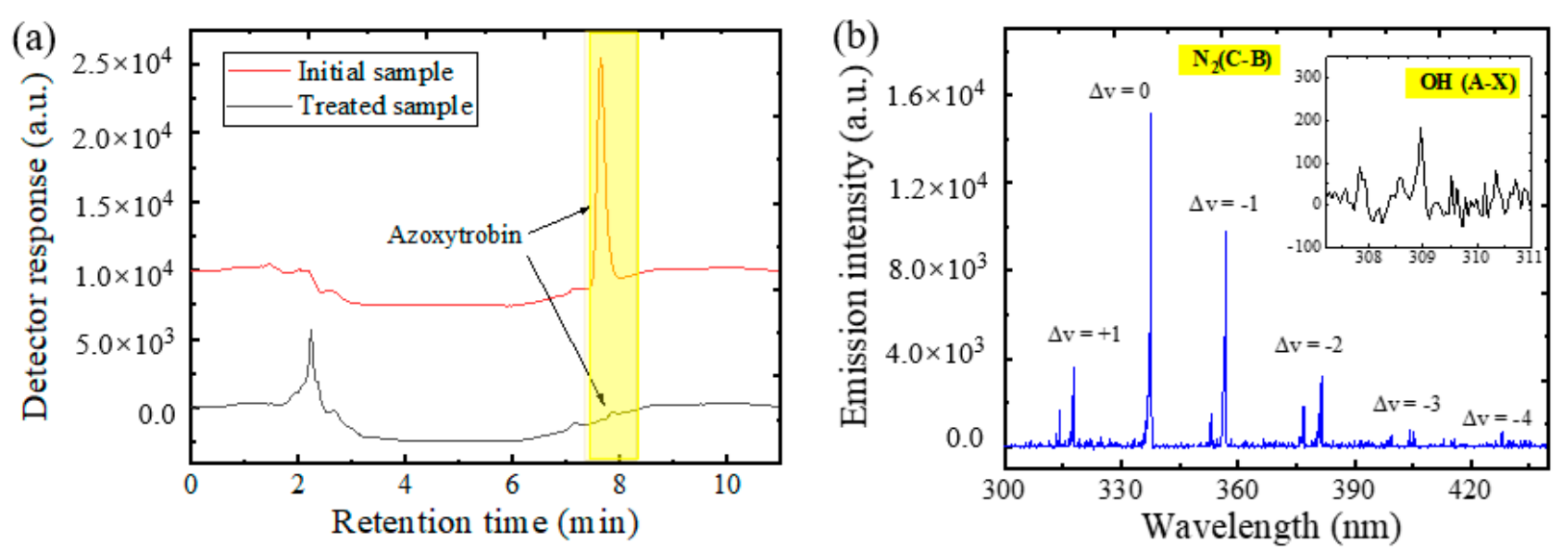

Figure 2. (a) Chromatographic fingerprints of azoxystrobin; (b) Optical emission spectra of the underwater air plasma ranging from $300-440 \mathrm{~nm}$.

The removal efficiency of model pollutants was better illustrated by the yield ( $\mathrm{Y}$, $\mathrm{g} /(\mathrm{kWh}))$, defined as the amount of azoxystrobin decomposed per unit of energy consumed in the process shown in Equation (2):

$$
\text { yield }=\frac{V \times C_{0} \times \eta}{P \times t}
$$

where $V$ was the solution volume $(\mathrm{L}) ; C_{0}$ was the concentration of azoxystrobin solution $(\mathrm{mg} / \mathrm{L}) ; \eta$ was the removal efficiency (\%); $P$ was the average power dissipated in the discharge $(\mathrm{W})$ and $t$ was the treatment time (h). Here, the average power $P$ was defined as Equation (3):

$$
P=\frac{1}{T} \int u(t) \cdot i(t) d t
$$

where $u(t)$ and $i(t)$ were the applied voltage $(\mathrm{V})$ and current $(\mathrm{A})$ respectively; $T$ was the period of AC waveform.

The removal process of azoxystrobin was assumed to follow pseudo-first-order kinetics and obeyed the following Equation (4):

$$
-k C=\frac{d C}{d t}
$$

where $k$ was the observed kinetic constant $\left(\mathrm{min}^{-1}\right)$ and $C$ was the concentration of azoxystrobin $(\mathrm{mg} / \mathrm{L})$.

In order to analyze the reactive species generated by the discharge, optical emission spectra (OES) in the range of 300-440 nm was measured by emission spectrometer (SP-2750, Princeton Instruments, USA), and the spectra was shown in Figure 2b. In the spectra, the bands of $\mathrm{N}_{2}(\mathrm{C}-\mathrm{B})$ and $\mathrm{OH}(\mathrm{A}-\mathrm{X})$ were observed. In air discharge, energy electrons collided with $\mathrm{N}_{2}$ and $\mathrm{H}_{2} \mathrm{O}$ molecules to produce the $\mathrm{N}_{2}(\mathrm{C})$ and $\mathrm{OH}$, respectively, as shown in 
reactions (R1) and (R2). Additionally, $\mathrm{OH}$ can be generated from the dissociation excitation of $\mathrm{H}_{2} \mathrm{O}$ molecules by $\mathrm{N}_{2}(\mathrm{C})$, as shown in Reactions (R3). The OES results showed that this gas-liquid discharge can generate strong, chemical reactive species that respond for the pollution degradation:

$$
\begin{aligned}
\mathrm{N}_{2}+e & \rightarrow \mathrm{N}_{2}(\mathrm{C})+e(\mathrm{R} 1) \\
\mathrm{H}_{2} \mathrm{O}+e & \rightarrow \mathrm{OH}(\mathrm{A})+\mathrm{H}(\mathrm{R} 2) \\
\mathrm{H}_{2} \mathrm{O}+\mathrm{N}_{2}(\mathrm{C}) & \rightarrow \mathrm{OH}(\mathrm{A})+\mathrm{N}_{2}(\mathrm{~A})(\mathrm{R} 3)
\end{aligned}
$$

For describing mass transfer, based on two-films theory [31,32], mass transfer model provided in the Supplementary Material (in Figure S1) connected the discharge with mass transfer between gas and liquid phases. The relevant Formulas (5)-(8) are used as:

$$
K_{g}\left(P_{g}-P_{l}^{*}\right)=K_{l}\left(C_{l}^{*}-C_{l}\right)
$$

where $K_{g}$ is overall mass transfer coefficient based on gas-phase concentration; $K_{l}$ was overall mass transfer coefficient based on liquid-phase concentration; $C_{g}^{*}$ was liquid film concentration of reactive species that would be in equilibrium with the bulk gas partial pressure $p_{g}$ of reactive species generated by air ionization and $p_{l}^{*}$ is gas film partial pressure of reactive species that would be in equilibrium with the concentration $C_{l}$ of bulk liquid phase. The gas mass transfer coefficient $\left(K_{g}\right)$ is commonly determined using the work from Pacheco [31]:

$$
K_{g}=\frac{S h D}{R T d}
$$

where $D$ is diffusivity, which can be calculated by Fuller formula $\left(D \propto T^{1.75}\right)$; $\mathrm{R}$ is the gas constant; $T$ is temperature; $d$ is hydraulic diameter and $S h$ is the Sherwood number that can be expressed as:

$$
1.075\left[\operatorname{ReSc}\left(\frac{d}{h}\right)\right]^{0.85}
$$

Here, Re is the Reynolds number; $S c$ is the Schmidt number and $h$ is the WWC (wetted wall column) length. The liquid film mass transfer coefficient is analytically approximated using Dugas' work [31]:

$$
K_{l}=\left(\frac{3^{\frac{1}{3}} 2^{\frac{1}{2}}}{\pi^{\frac{1}{2}}}\right)\left(\frac{Q^{\frac{1}{3}} h^{\frac{1}{2}} W^{\frac{2}{3}}}{A}\right)\left(\frac{g \rho}{\mu}\right)^{\frac{1}{6}} D^{\frac{1}{2}}
$$

where $Q$ is solvent volumetric flow rate; $W$ is circumference of the WWC; $A$ is the gas-liquid contact area; $g$ is the gravitational constant; $A$ is density and $B$ is dynamic viscosity. The Formulas (6) and (8) clearly showed that the temperature played an important role on the value of mass transfer rate. Additionally, the total mass transfer quantity was proportional to the concentration of the reactive species multiplied by the mass transfer time and the mass transfer rate in the bubbles.

The E. coli (Escherichia coli) bacterial culture with the initial concentration of $10^{5} \mathrm{CFU} / \mathrm{mL}$ (colony-forming unit $/ \mathrm{mL}$ ) was used for the toxicity test. The bacterial culture was inoculated in nutrient broth and incubated at $37^{\circ} \mathrm{C}$ for $24 \mathrm{~h}$ after which $0.1 \mathrm{~mL}$ of bacterial suspension was drawn out, mixed thoroughly with $0.9 \mathrm{~mL}$ aqueous solution (sterile water, azoxystrobin solution and treated azoxystrobin solution) and immediately spun onto the surface of sterile nutrient broth agar plates $(90 \mathrm{~mm}$ diameter) which were then incubated at $37^{\circ} \mathrm{C}$ for some time to facilitate initial growth.

\section{Results and Discussion}

\subsection{Effect of Voltage}

As illustrated in Figure 3a, the concentrations of azoxystrobin solution treated by gas-liquid discharge under various input voltages with the discharge frequency of $6 \mathrm{kHz}$ 
and gas flow rate of 1.5 SLM were analyzed. When treatment time reached $9 \mathrm{~min}$, the removal efficiencies of azoxystrobin solution were $98.1 \%$ and $98.7 \%$ with input voltage of $8 \mathrm{kV}$ and $10 \mathrm{kV}$, respectively. It obviously indicated that when the treatment time increased, the removal efficiency of azoxystrobin solution showed two stages. When the treatment time increased from 0 to $1 \mathrm{~min}$, azoxystrobin was decomposed sharply, and then, after $1 \mathrm{~min}$ treatment, the removal efficiency of azoxystrobin solution slowly increased from $50 \%$ to over $80 \%$.
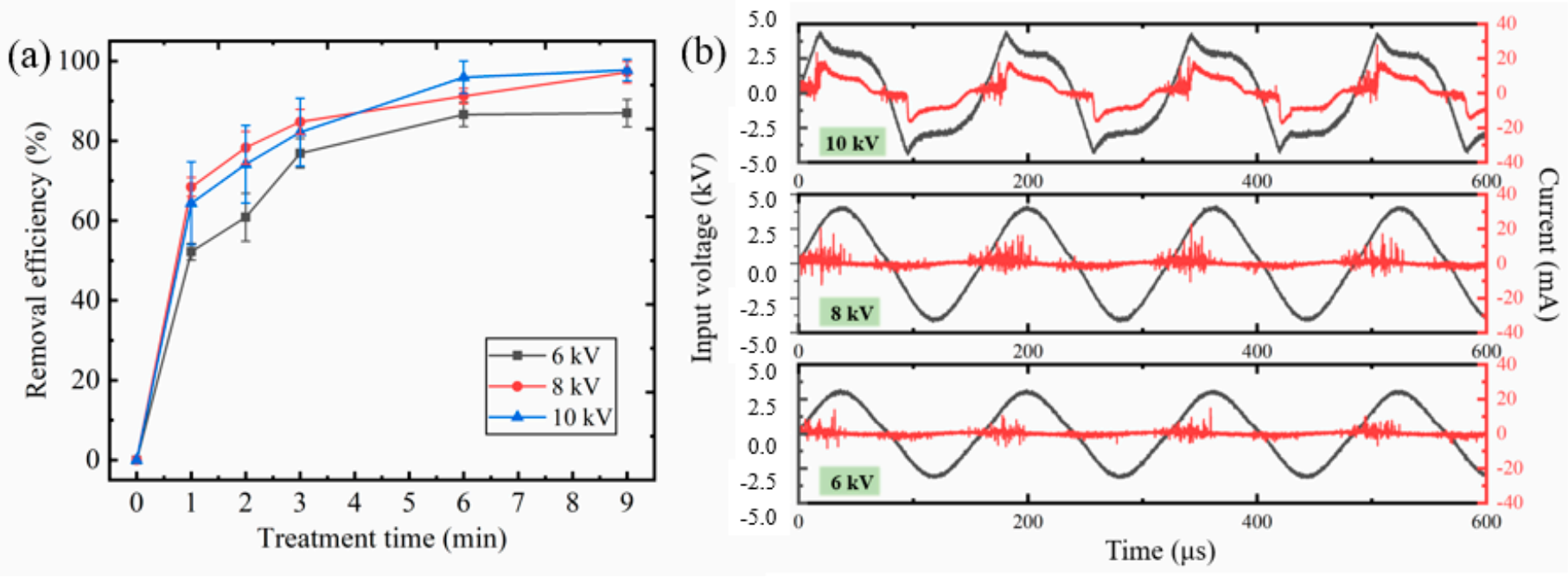

Figure 3. (a) Effect of input voltage on the removal efficiency of azoxystrobin as the function of treatment time; (b) The waveforms of input voltage and current.

The waveforms of input voltage and discharge current were shown in Figure $3 b$. When the input voltage was $6 \mathrm{kV}$, the current waveform mainly consisted of a series of short-lived current filaments and the direction and intensity of these filaments were different in the positive high voltage and negative high voltage cycle. The present time of filamentary currents lasts from 50 to $52 \mu \mathrm{s}$. The intensity of filamentary currents in the positive high voltage cycle was higher than that in the negative high voltage cycle, which indicated that the discharge is severe in the positive high voltage cycle. When the input voltage increased to $8 \mathrm{kV}$, both the intensity of filamentary currents and duration time of the discharge were significantly enhanced. However, when the input voltage increased to $10 \mathrm{kV}$, the discharge was unstable and the discharge mode converts from filament to spark or arc [33]. So, it was believed that in the same discharge mode, when the input voltage varied from 6 to $8 \mathrm{kV}$, both the generation and the activity of reactive species increased due to the energy injection in the discharge region. Meanwhile, the gas temperature increased as the input voltage increased as well. According to Fuller Formula, diffusivity (D) was directly proportional to $T^{1.75}$. According to the Formula (6), when the gas temperature increased, $K_{g}$ increased, which was a benefit for the mass transfer in gas phase. Compared with the gas temperature, the aqueous solution temperature was relatively constant. Thus, $K_{l}$ was constant according to the Formula (8). So, total mass transfer quantity of reactive species presented a rising trend, which directly led to the increase of removal efficiency of azoxystrobin. When the input voltage continuously increased to $10 \mathrm{kV}$, the discharge mode transferred from diffuse mode to arc mode. In the arc discharge, strong contractive discharge channels quickly formed and the injection energy increased obviously, leading to the sharp increase of gas temperature, which was a benefit for the generation and the activity of reactive species. Meanwhile, because of the obvious increase of the discharge intensity, the stability of the gas bubbles on the tube nuzzle became poor. Due to the strong shock waves generated by the strong discharge channels, the break process of the gas bubbles was significantly speeded up. This meant that the mass transfer time decreased 
greatly. So, total mass transfer quantity showed no remarkable increase and the removal efficiencies of azoxystrobin with the input voltage of $8 \mathrm{kV}$ and $10 \mathrm{kV}$ were quite similar.

Due to chaotic changes of filamentary current, the average input power $(\mathrm{P})$ was used to evaluate the consumption of the discharge and was calculated by Formula (3). Yield and pseudo first-order kinetic constant were calculated by Formulas (2) and (4). The relative results were listed in Table 1. It was shown that with the input voltage increasing, the power consumption increased as well as the removal efficiency. When the input voltage increased from 6 to $10 \mathrm{kV}$, the power consumption increased dramatically from 1.19 to $12.62 \mathrm{~W}$. The yield decreased from 1.17 to $0.12 \mathrm{~g} /(\mathrm{kW} \cdot \mathrm{h})$. The pseudo first-order kinetic constant increased from 0.16 to $0.37 \mathrm{~min}^{-1}$ and the removal efficiency increased from $86.9 \%$ to $98.7 \%$. The results in Table 1 were consistent with the results in Figure 3a,b.

Table 1. Effect of relevant parameters such as input voltage, power, yield and pseudo first-order kinetic constant on the removal efficiency with the treatment time of $9 \mathrm{~min}$.

\begin{tabular}{|c|c|c|c|c|c|}
\hline \multirow{2}{*}{$\begin{array}{c}\text { Input Voltage } \\
(\mathbf{k V})\end{array}$} & \multirow{2}{*}{$\begin{array}{l}\text { Power } \\
\text { (W) }\end{array}$} & \multirow{2}{*}{$\begin{array}{c}\text { Yield } \\
(\mathrm{g} /(\mathrm{kW} \cdot \mathrm{h}))\end{array}$} & \multicolumn{2}{|c|}{ Pseudo First-Order Kinetic Constant } & \multirow{2}{*}{$\begin{array}{l}\text { Removal } \\
\text { Efficiency }\end{array}$} \\
\hline & & & $k\left(\min ^{-1}\right)$ & $\mathbf{R}^{2}$ & \\
\hline 6 & 1.19 & 1.17 & 0.16 & 0.883 & $86.9 \%$ \\
\hline 8 & 2.14 & 0.73 & 0.30 & 0.964 & $98.1 \%$ \\
\hline 10 & 12.62 & 0.12 & 0.37 & 0.937 & $98.7 \%$ \\
\hline
\end{tabular}

\subsection{Effect of Gas Flow Rate}

The influence of gas flow rate on azoxystrobin decomposed by gas-liquid discharge is depicted in Figure 4a. With the input voltage of $8 \mathrm{kV}$ and frequency of $6 \mathrm{kHz}$, as the gas flow rate varied from 0.7 to 5 SLM, it can be seen clearly that the removal efficiency of azoxystrobin presented first increased and then decreased. With the treatment time of $9 \mathrm{~min}$, the removal efficiency increased from $94.2 \%$ to $98.1 \%$ when the gas flow rate increased from 0.7 to $1.5 \mathrm{SLM}$, as shown in Figure $4 \mathrm{~b}$. When the gas flow rate continued to increase, the removal efficiency decreased and when the gas flow rate was 5 SLM, the removal efficiency decreased to $87.0 \%$.

(a)

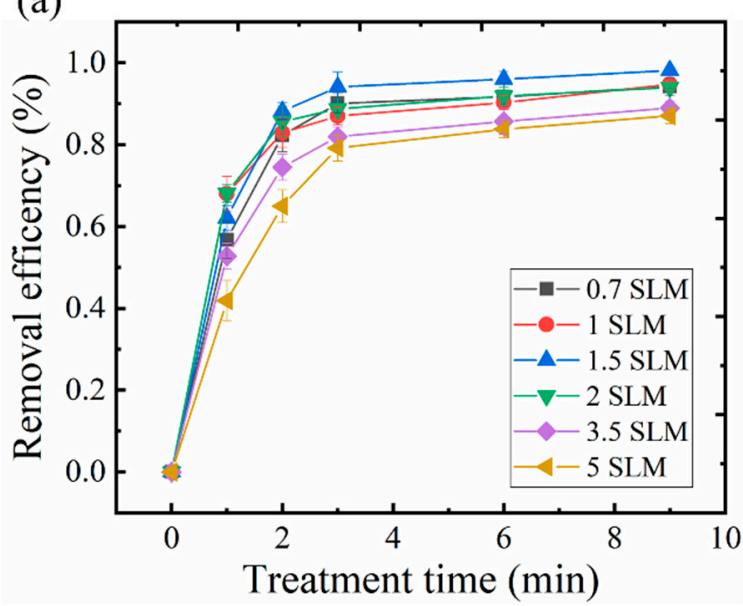

(b)

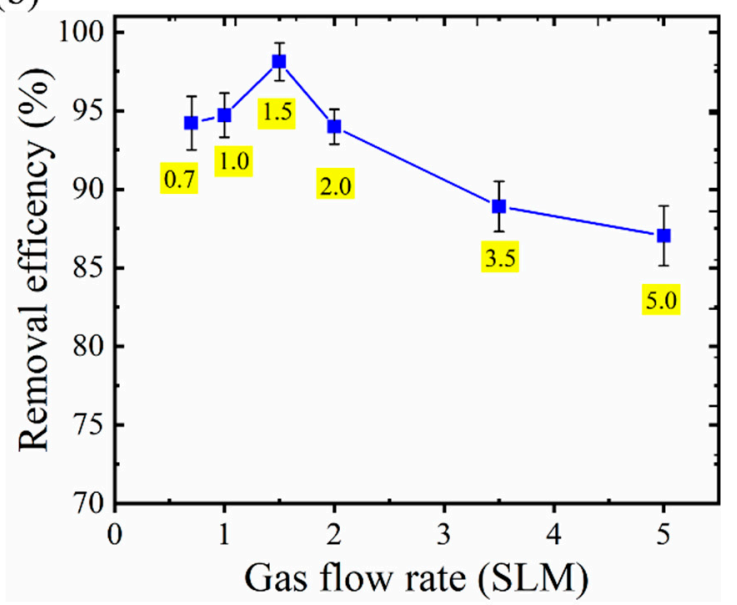

Figure 4. (a) Effect of gas flow rate on the removal efficiency of azoxystrobin and (b) the removal efficiency of azoxystrobin at different gas flow in 9 min treatment.

Due to the input voltage being constant, both generation and activity of reactive species were constant, and gas temperature in the discharge region and aqueous solution temperature were unchanged, which indicated that the whole mass transfer rates in both gas phase and liquid phase were constant, according to Formulas (6) and (8). So, the removal efficiency of azoxystrobin was resulted by the total mass transfer quantity of the 
reactive species, and the total mass transfer quantity was mainly dependent on the mass transfer quantity per bubble. According to the digital camera images as shown in Figure 4, we built up an ideal and simple gas bubble model. We supposed the bubble as a sphere with the diameter of $1.93 \mathrm{~mm}$, which was obtained by digital camera as shown in Figure 5. and every gas bubble was the same. By using the approximation method, it was feasible to study whole removal processes. The relationship between discharge times per bubble and bubble numbers per second was studied.

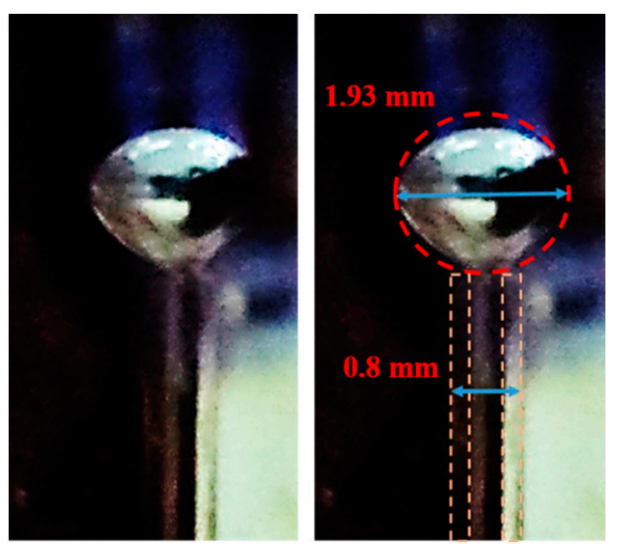

Figure 5. The image of the underwater bubble.

For 15 quartz capillaries, the gas flow rate in a single quartz tube should be onefifteenth of the total gas flow rate. The gas bubble volume was calculated by the volume of the sphere $\left(\frac{4}{3} \pi \cdot R^{3}\right)$ and gas flow rate $(v)$; number of bubble $(N)$ blowing out per second was calculated according to Equation (8):

$$
N=\frac{v}{20 \pi \cdot\left(\frac{d}{2}\right)^{2}}
$$

where $d$ was the maximum diameter of bubble when it detached from capillary. The discharge frequency was $6 \mathrm{kHz}$. Comparing the number of bubbles generated in one capillary per second, the number of discharge times per bubble can be obtained. The results were shown in Table 2. It presented that as the gas flow rate increased from 0.7 to 5.0 SLM, the number of bubbles per second in a single capillary increased significantly from 200.4 to 1401.9 and the corresponding number of discharge times gradually decreased from 29.9 to 4.2. When the radius of the quartz tube, the depth of solution and the aqueous solution temperature were constants, it indicated that the force which held the bubble stably on the tube nuzzle was a constant. So, when the gas flow rate increased, the inner pressure of the bubble increased quickly and the time of bubble disengagement from tube nuzzle reduced, which meant the mass transfer time was shortened. However, when the gas flow rate increased, it was a benefit for the diffusion process of the reactive species resulting in the increase of the mass transfer rate in the bubble. So, the gas flow rate affected both the mass transfer time and mass transfer rate in the bubble. Moreover, the experimental results indicated that when the gas flow rate was $1.5 \mathrm{SLM}$, total mass transfer quantity of reactive species was optimum. 
Table 2. The number of discharge times under different gas flow rate.

\begin{tabular}{ccc}
\hline Gas Flow Rate & $\begin{array}{c}\text { Bubble Number per } \\
\text { Capillary per Second (N/s) }\end{array}$ & $\begin{array}{c}\text { Number of Discharges in a } \\
\text { Single Bubble (Theoretical } \\
\text { Value) }\end{array}$ \\
\hline 0.7 SLM & 200.4 & 29.9 \\
1.5 SLM & 429.5 & 14.0 \\
2.0 SLM & 560.7 & 10.7 \\
3.5 SLM & 1001.7 & 6.0 \\
5.0 SLM & 1401.9 & 4.2 \\
\hline
\end{tabular}

\subsection{Effect of Initial Solution Temperature}

Temperature was a key point on the generation of reactive species, which can affect the chemical reaction rate and the mass transfer rate during the removal process. So, experiment of the effect of initial solution temperature on the removal efficiency was carried out. The experimental results showed that the removal efficiency of azoxystrobin showed two stages in Figure 6a. This may be resulted by chemical reactions during the degradation processes. In the first stage, the concentration of reactive species was low and the concentration of azoxystrobin was relatively high. So, it was good for the mass transfer in the gas-liquid interface layer and azoxystrobin was apace decomposed. It showed a sharp increasement trend. Especially, the higher the initial solution temperature was, the more quickly the azoxystrobin decomposed in this stage. Then, due to the increasement of the by-product concentration, the competition between azoxystrobin and degradation by-product in solution played the dominant role and the removal processes slowed down. Additionally, due to the existence of heat exchange between the initial solution temperature and room temperature (about $300 \mathrm{~K}$ ), the degradation processes became complicated by the long-time treatment. Figure $6 \mathrm{a}$ showed that when the treatment time reached 9 min with the initial solution temperature varying from $278 \mathrm{~K}$ to $323 \mathrm{~K}$, the removal efficiencies achieved up to $85 \%$. With the initial solution temperature increasing to $343 \mathrm{~K}$, the removal efficiency reduced to $81.34 \%$. The reason was that when the initial solution temperatures were below room temperature, the mass transfer rate increased as the initial solution temperature increased. When the initial solution temperatures were over room temperature, the mass transfer rate increased as the initial solution temperature increased. Meanwhile, the thermal instability of underwater gas bubble caused by the increasement of surrounding temperature should be considered. High surrounding temperature resulted in the bubble early escaping from the tube nuzzle. This indicated that the mass transfer time was greatly shortened, which was not conductive to total mass transfer quantity of reactive species as well as to the removal efficiency. Considering all these effects, when the initial solution temperature increased above the room temperature, the removal efficiency became low.

In Figure $6 \mathrm{~b}$, it can be observed that the removal processes of azoxystrobin follow the pseudo first-order kinetic model. The detailed pseudo first-order kinetic constant was shown in Table S1 (in the Supplementary Materials) under different initial solution temperatures. When the initial solution temperature varied from $278 \mathrm{~K}$ to $297 \mathrm{~K}$, the slope of the curve increased and reached the maximum $0.376 \mathrm{~min}^{-1}$ at $297 \mathrm{~K}$. When the initial solution temperature steadily increased, the slope of the curve decreased. The variation trend was consistent with the previous results in Figure 6a. 

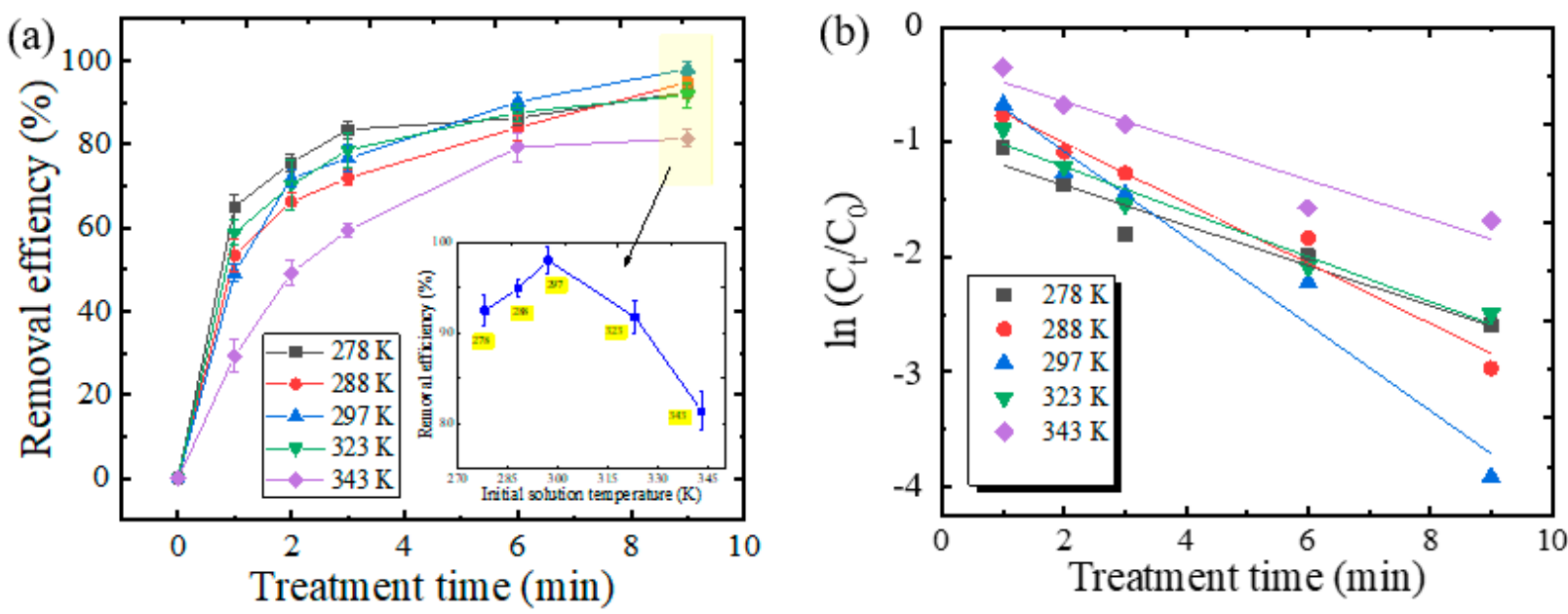

Figure 6. (a) Effect of initial solution temperature on the removal efficiency of azoxystrobin; (b) The pseudo first-order rate kinetics curve of azoxystrobin degradation under different initial solution temperature.

\subsection{Removal Pathway Analysis}

The LC-MS was applied to analyze the feasible removal pathway of azoxystrobin, and its detailed parameters were shown in the Supplementary Material (in Table S2). The chromatogram of azoxystrobin with various treatment times was shown in Figure 7a. There was an obvious peak in the chromatogram of azoxystrobin without discharge treatment. This peak, with the retention time of $13.93 \mathrm{~min}$, mainly belonged to untreated azoxystrobin sample. At the same time, with the retention time of $7.14 \mathrm{~min}, 8.02 \mathrm{~min}$ and $8.57 \mathrm{~min}$, three small spikes appeared. When the treatment time was $3 \mathrm{~min}$, the values of these three spikes clearly increased and the value of the chromatogram peak of azoxystrobin decreased sharply. The mass charge ratios of these four peaks were given out in Figure $7 \mathrm{~b}$, which were $404,396,340$ and 283, respectively, when the relative retention time were $13.93 \mathrm{~min}, 8.57 \mathrm{~min}$, $8.02 \mathrm{~min}$ and $7.14 \mathrm{~min}$. When the treatment time increased to $9 \mathrm{~min}$, the chromatogram peak of azoxystrobin disappeared and those three spikes clearly decreased. Therefore, we can suppose that the main components in the original sample were azoxystrobin and these three by-products caused by natural decomposition. When the solution was treated by plasma, azoxystrobin component was quickly decomposed into these three byproducts and the contents of these three byproducts increased. When the plasma treatment continued, azoxystrobin component was totally removed and the three by-products decomposed into other small species.

In order to exclude effects of impurity introduction, only the peaks with mass charge ratio below 404 were considered, and the mass spectrum of the products produced by $9 \mathrm{~min}$ discharge treatment with the retention time accumulated from 0 to 20 min was shown in Figure 8. It clearly showed that azoxystrobin further decomposed into the matters with the mass of 396, 351, 340, 283, 122, 73 and 61 . It was worthwhile to note that the intensity of azoxystrobin molecular ions peak in Figure $8 \mathrm{~b}$ was one order of magnitude lower than untreated sample in Figure 8a. According to the mass spectrum result of 9 min treatment azoxystrobin sample, two removal pathways were proposed and shown in Figure 9.

One way was that the nitrile group in the benzene ring of $\mathrm{C} 0$ undergoes hydrolysis and rearrangement reactions under acidic and oxidative conditions and then gradually degraded. By the effects of hydrolysis reaction and rearrangement reaction under the acid condition, the nitrile group $(\mathrm{C} \equiv \mathrm{N})$ reacted with hydrogen ion and water molecule, forming a carbon-oxygen double bond [34]. That resulted in the formation of C1 (2-(2((6-(2-(aminomethyl) phenoxy) pyrimidin-4-yl) oxy) phenyl)-3-methoxypropanoic acid, $\mathrm{M}^{+}$396). Due to the instability of peptide bonds under acidic conditions [35], they were easily hydrolyzed and formed a carboxylic acid group. By the continuous attack of actives species, the pyrimidine ring was broken and the side chain of benzene was also oxidized 
to carboxyl group [36]. As the ether bond was polar and there was a pair of lone electrons on the oxygen atom, it was prone to breakage in a strong acid environment [37]. So, C5 (benzoic acid, $\mathrm{M}^{+} 122$ ) was generated.
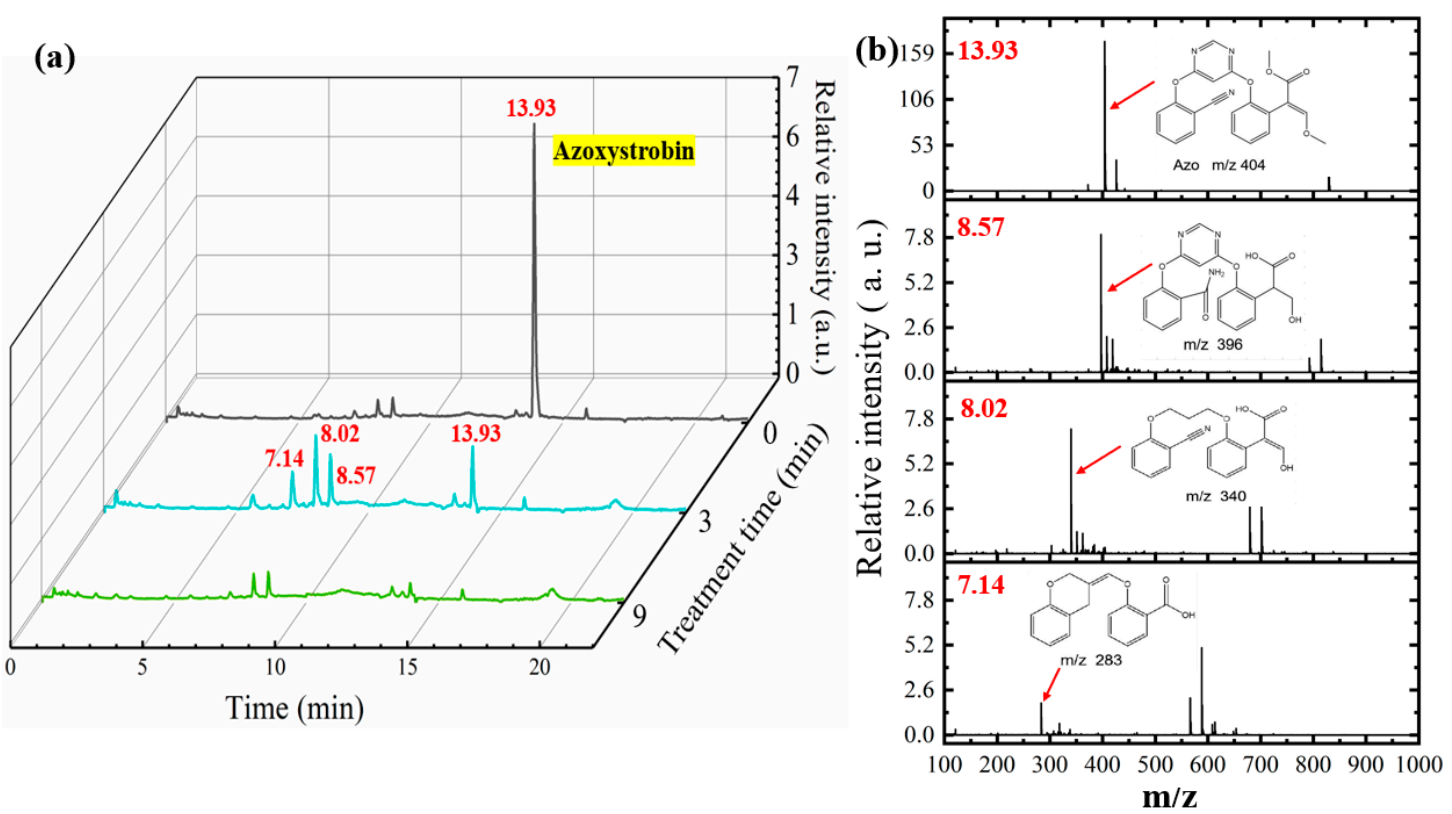

Figure 7. (a) Chromatogram of azoxystrobin solution sample and (b) mass spectrum analysis according to the retention time of chromatogram.
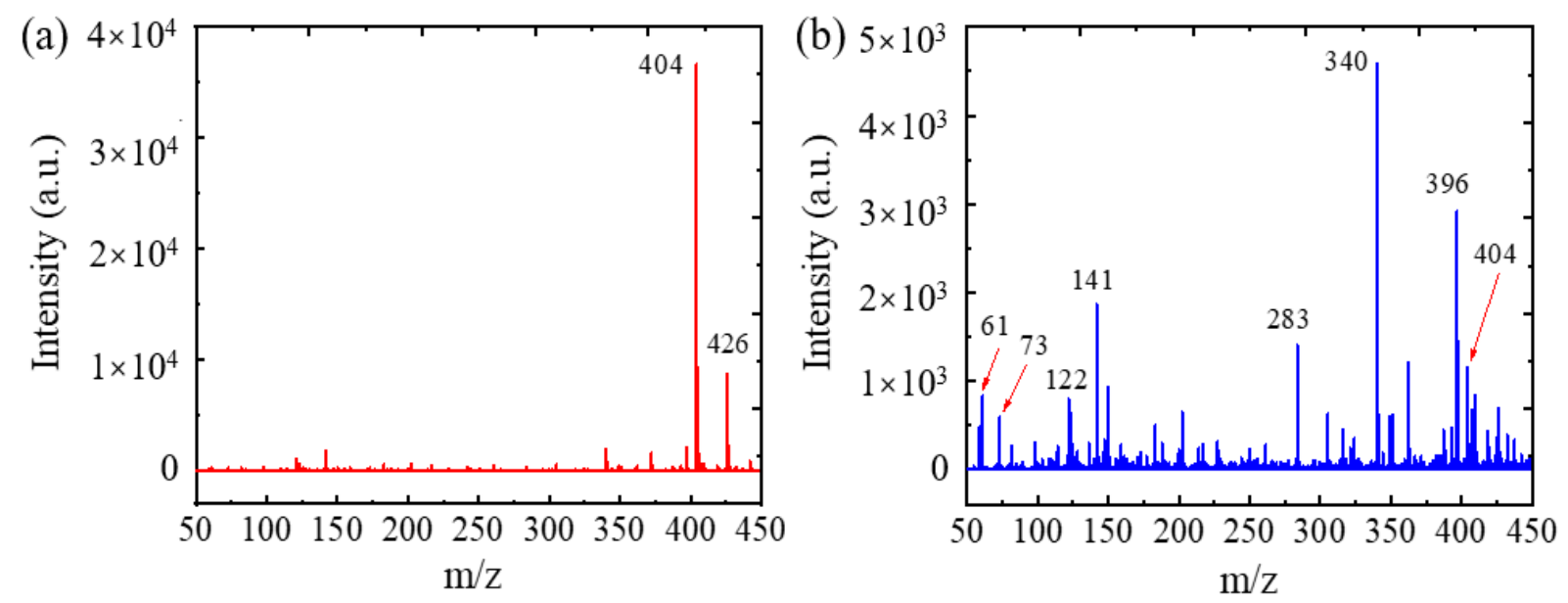

Figure 8. Mass spectrum of (a) untreated azoxystrobin sample and (b) the azoxystrobin sample under 9 min treatment. 


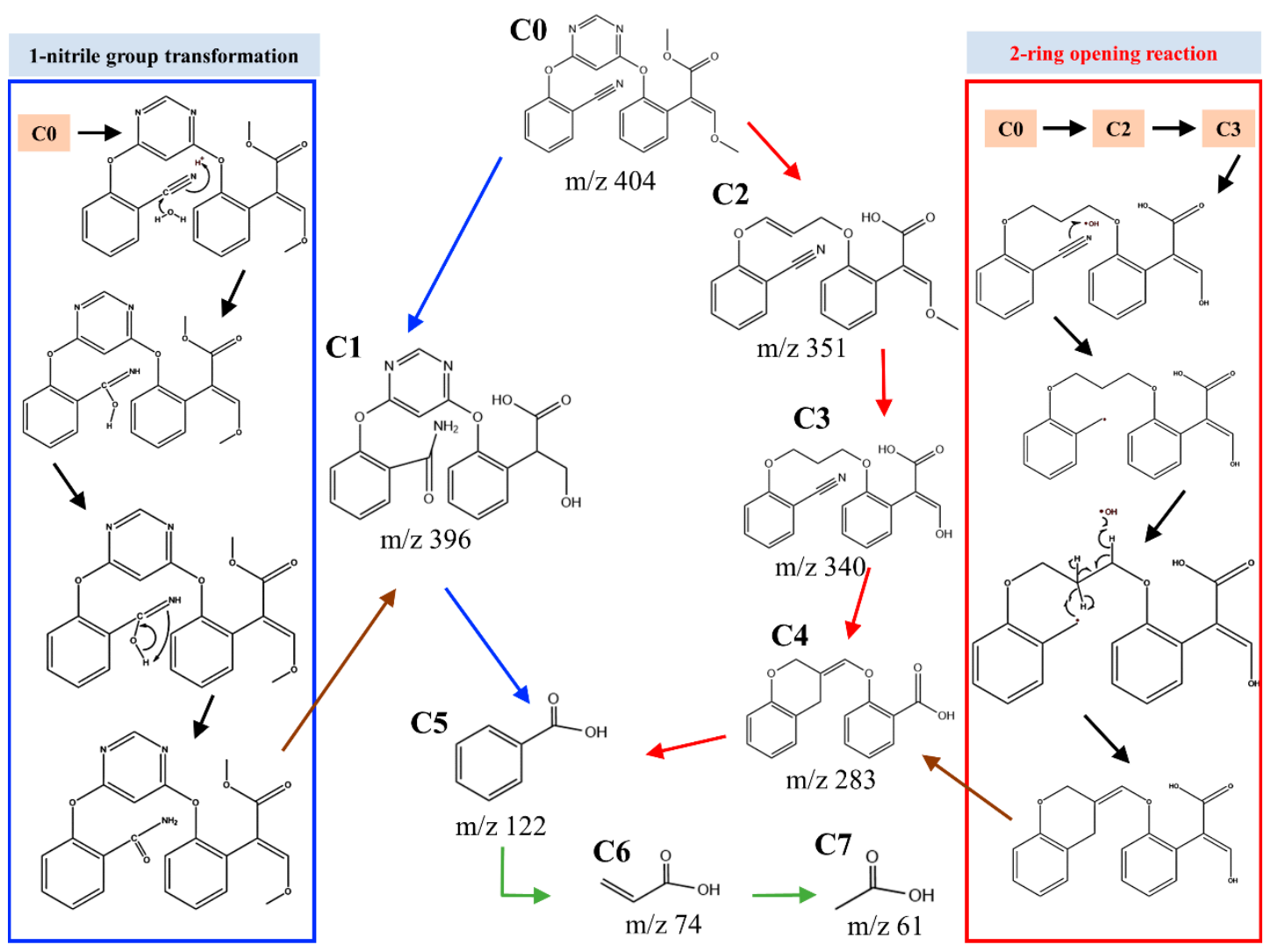

Figure 9. The removal pathway of azoxystrobin sample.

Another way was that the pyrimidine ring of azoxystrobin molecule (C0) undergoes a ring-opening reaction and then was gradually mineralized. By the attack of active species, $\mathrm{C}-\mathrm{N}$ bonds and $\mathrm{C}=\mathrm{N}$ bonds in the pyrimidine ring of $\mathrm{C} 0$ and ester group of $\mathrm{C} 0$ were broken and led to the formation of C2 ((E)-2-(2-((E)-3-(2-cyanophenoxy) allyl) oxy) phenyl)-3-methoxyacrylic acid, $\left.\mathrm{M}^{+} 351\right)$. When the discharge was going on, the $\mathrm{pH}$ value of the solution measured by $\mathrm{pH}$ meter (AZ-86505, Taiwan, China) decreased to about 2.6 and under this acidic condition, the $\mathrm{C}-\mathrm{O}$ bond in the ether bond was broken. Meanwhile, hydrogen ion attacked the $\mathrm{C}=\mathrm{C}$ bond resulting in electrophilic additions [38] and the predominant intermediate C3 ((E)-2-(2-(3-(2-cyanophenoxy)propoxy)phenyl)-3hydroxyacrylic acid, $\mathrm{M}^{+} 340$ ) was formed. With further treatment of hydroxyl radicals, $\mathrm{C} \equiv \mathrm{N}$ bond of $\mathrm{C} 3$ was broken and a benzyl radical was formed. Due to the delocalization of the free electron, the benzyl radical featured relatively high stability [39]. The benzyl radical attacked a nearby carbon, and the hydrogen radical reacted with the $\alpha$ hydrogen atom and generated a $\mathrm{H}_{2} \mathrm{O}$ molecule. As a result, the $\mathrm{C}=\mathrm{C}$ bond was formed between $\alpha$ carbon and $\beta$ carbon. Under the acidic and oxidative environment, the branch hydrocarbon was easily and directly oxidized as benzoic acid and C4 ((E)-2-(chroman-3-ylidenemethoxy) benzoic acid, $\mathrm{M}^{+} 283$ ) was generated. Then, two ether bonds of $C 4$ were broken and the side chain alkanes on the benzene ring were oxidized into carboxylic acid groups. This resulted in the generation of two $\mathrm{C} 5$ (benzoic acid, $\mathrm{M}^{+} 122$ ) molecules.

With further plasma treatment, the phenyl group of $\mathrm{C} 5$ was ring-opened and became $\mathrm{C} 6$ (acrylic acid, $\mathrm{M}^{+} 74$ ). Then, the $\mathrm{C}=\mathrm{C}$ bond was split and acrylic acid became $\mathrm{C} 7$ (acetic acid, $\mathrm{M}^{+}$61). At last, all these degradation products will decompose into some non-toxic inorganic substances such as carbon dioxide, water, nitrate, nitrite and so on.

\subsection{Toxicity Measurements}

The degradation by gas-liquid discharge is expected to remove the toxic pollutants present in the solution. As shown in Figure 10, we have studied the toxicity of a plasma 
treated sample. The inhibition of growth of E. coli was studied for assessing the toxicity of decomposed azoxystrobin solution. It was observed that untreated azoxystrobin solution produced inhibition character while the NTP treated sample did not exhibited any inhibition character, thereby indicating their non-toxic nature.

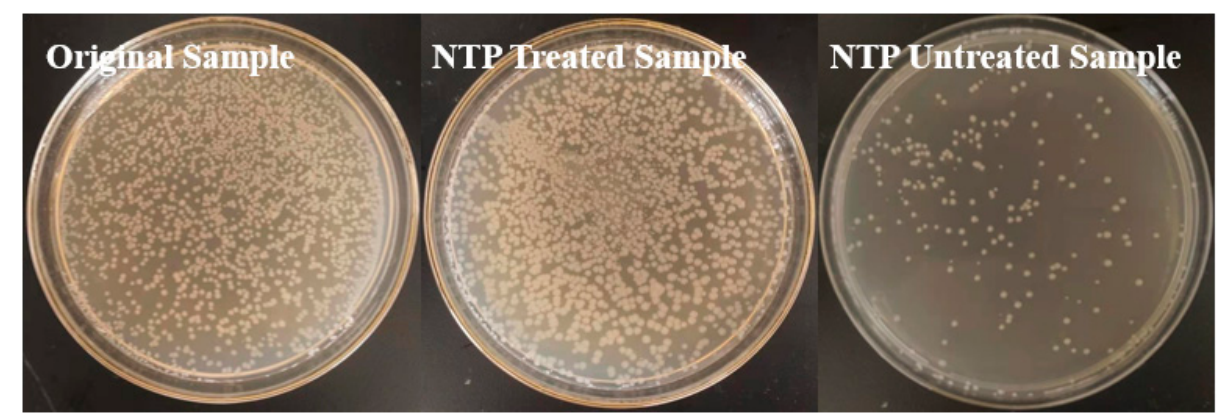

Figure 10. Study on the toxicity of NTP treated azoxystrobin sample against Escherichia coli.

\section{Conclusions}

In conclusion, the high efficiency of the gas-liquid discharge generated by the microsized discharge array on the degradation of azoxystrobin has been verified, and with the applied voltage of $8 \mathrm{kV}$, discharge frequency of $6 \mathrm{kHz}$, gas flow rate of $1.5 \mathrm{SLM}$ and initial solution temperature of $297 \mathrm{~K}$, the removal efficiency of azoxystrobin can reach as high as $98.1 \%$ after 9 min discharge treatment. During the studies, it is found that the total mass transfer quantity of reactive species generated by the gas-liquid discharge plays an important role in the degradation process and this total mass transfer quantity is mainly dependent on the concentration of reactive species, mass transfer rate and mass transfer time in the underwater bubbles, which are deeply affected by the input energy of the discharge, the hold time of the bubbles on the tube nuzzle and the temperature. The LC-MS results show that there are two ways for azoxystrobin degradation, in which they are the conversion of nitrile group to carboxyl group and pyrimidine ring-opening, and the final products are proved to be non-toxic. Therefore, this detailed degradation pathway may provide a safe, reliable and effective method to purify the organic wastewater.

Supplementary Materials: The following are available online at https:/ / www.mdpi.com/article/10 .3390 /catal11101169/s1, Figure S1: Mass transfer model of reactive species in a bubble, Table S1: The pseudo-first-order kinetic constant under different initial solution temperature, Table S2: The main parameters of LC-MS for the analysis of decomposed products.

Author Contributions: Data curation, Y.K.; Formal analysis, F.C. and Y.S.; Funding acquisition, Y.K.; Investigation, F.C.; Project administration, D.Y.; Resources, Y.S.; Supervision, D.Y. and F.Y.; Writing—original draft, F.C.; Writing—review \& editing, Y.S. All authors have read and agreed to the published version of the manuscript.

Funding: This research was funded by National Natural Science Foundation of China, grant number 11705023,11965018 and 51967018.

Conflicts of Interest: The authors declare no conflict of interest.

\section{References}

1. Cooper, J.; Dobson, H. The benefits of pesticides to mankind and the environment. Crop Prot. 2007, 26, 1337-1348. [CrossRef]

2. Pretty, J. Intensification for redesigned and sustainable agricultural systems. Science 2018, 362. [CrossRef] [PubMed]

3. Huisman, J.; Codd, G.A.; Paerl, H.W.; Ibelings, B.W.; Verspagen, J.M.; Visser, P.M. Cyanobacterial blooms. Nat. Rev. Microbiol. 2018, 16, 471-483. [CrossRef] [PubMed]

4. Lu, T.; Zhang, Q.; Lavoie, M.; Zhu, Y.; Ye, Y.; Yang, J.; Paerl, H.W.; Qian, H.; Zhu, Y.G. The fungicide azoxystrobin promotes freshwater cyanobacterial dominance through altering competition. Microbiome 2019, 7, 128. [CrossRef]

5. Rodrigues, E.T.; Lopes, I.; Pardal, M.A. Occurrence, fate and effects of azoxystrobin in aquatic ecosystems: A review. Environ. Int. 2013, 53, 18-28. [CrossRef] [PubMed] 
6. The Japan Food Chemical Research Foundation. Maximum Residue Limits (MRLs) List of Agricultural Chemicals in Foods [EB/OL]. 2020. Available online: http:/ /db.ffcr.or.jp/front/pesticide_detail?id=3500 (accessed on 3 February 2021).

7. Xu, Y.; Li, B.; Hou, K.; Du, Z.; Allen, S.C.; Zhu, L.; Li, W.; Zhu, L.; Wang, J.; Wang, J. Ecotoxicity evaluation of azoxystrobin on Eisenia fetida in different soils. Environ. Res. 2021, 194, 110705. [CrossRef]

8. Cao, F.; Zhu, L.; Li, H.; Yu, S.; Wang, C.; Qiu, L. Reproductive toxicity of azoxystrobin to adult zebrafish (Danio rerio). Environ. Pollut. 2016, 219, 1109-1121. [CrossRef]

9. Vieira, R.S.; Venâncio, C.A.; Félix, L.M. Embryonic zebrafish response to a commercial formulation of azoxystrobin at environmental concentrations. Ecotoxicol. Environ. Saf. 2021, 211, 111920. [CrossRef]

10. Franke, C.; Studinger, G.; Berger, G.; Böhling, S.; Bruckmann, U.; Cohors-Fresenborg, D.; Jöhncke, U. The assessment of bioaccumulation. Chemosphere 1994, 29, 1501-1514. [CrossRef]

11. Xu, C.; Lin, X.; Yin, S.; Zhao, L.; Liu, Y.; Liu, K.; Li, F.; Yang, F.; Liu, W. Enantioselectivity in biotransformation and bioaccumulation processes of typical chiral contaminants. Environ. Pollut. 2018, 243, 1274-1286. [CrossRef]

12. Posch, T.; Köster, O.; Salcher, M.; Pernthaler, J. Harmful filamentous cyanobacteria favoured by reduced water turnover with lake warming. Nat. Clim. Chang. 2012, 2, 809-813. [CrossRef]

13. Nawrocki, J.; Kasprzyk-Hordern, B. The efficiency and mechanisms of catalytic ozonation. Appl. Catal. B Environ. 2010, 99, 27-42. [CrossRef]

14. Rodriguez-Peña, M.; Barrios, J.; Becerril-Bravo, E.; Rodrigo, M.; Barrera-Díaz, C. Degradation of endosulfan by a coupled treatments in a batch reactor with three electrodes. Fuel 2020, 281, 118741. [CrossRef]

15. Yang, L.; Liya, E.Y.; Ray, M.B. Degradation of paracetamol in aqueous solutions by $\mathrm{TiO}_{2}$ photocatalysis. Water Res. 2008, 42 , 3480-3488. [CrossRef] [PubMed]

16. Heo, I.; Kim, M.K.; Sung, S.; Nam, I.-S.; Cho, B.K.; Olson, K.L.; Li, W. Combination of Photocatalysis and HC/SCR for Improved Activity and Durability of DeNOx Catalysts. Environ. Sci. Technol. 2013, 47, 3657-3664. [CrossRef]

17. Frontistis, Z.; Daskalaki, V.M.; Katsaounis, A.; Poulios, I.; Mantzavinos, D. Electrochemical enhancement of solar photocatalysis: Degradation of endocrine disruptor bisphenol-A on Ti/ $\mathrm{TiO}_{2}$ films. Water Res. 2011, 45, 2996-3004. [CrossRef] [PubMed]

18. Rodríguez-Peña, M.; Pérez, J.A.B.; Llanos, J.; Sáez, C.; Rodrigo, M.A.; Barrera-Díaz, C.E. New insights about the electrochemical production of ozone. Curr. Opin. Electrochem. 2021, 27, 100697. [CrossRef]

19. Zong, Z.; Zhou, R.; Liu, D.; Song, Y.; Niu, J. Treatment of omethoate on edible wolfberry by atmospheric pressure air surface dielectric barrier discharge. Plasma Process. Polym. 2016, 13, 402-409. [CrossRef]

20. Magureanu, M.; Mandache, N.B.; Parvulescu, V.I. Degradation of pharmaceutical compounds in water by non-thermal plasma treatment. Water Res. 2015, 81, 124-136. [CrossRef] [PubMed]

21. Chen, C.; Liu, D.X.; Liu, Z.C.; Yang, A.J.; Chen, H.L.; Shama, G.; Kong, M.G. A model of plasma-biofilm and plasma-tissue interactions at ambient pressure. Plasma Chem. Plasma Process. 2014, 34, 403-441. [CrossRef]

22. Bruggeman, P.; Leys, C. Non-thermal plasmas in and in contact with liquids. J. Phys. D Appl. Phys. 2009, 42, 053001. [CrossRef]

23. Michael, G.K.; Liu, D.X. Researches on the Interaction Between Gas Plasmas and Aqueous Solutions: Significance, Challenges and New Progresses. High Volt. Eng. 2014, 40, 2956-2965.

24. Graves, D.B. The emerging role of reactive oxygen and nitrogen species in redox biology and some implications for plasma applications to medicine and biology. J. Phys. D Appl. Phys. 2012, 45, 263001. [CrossRef]

25. Malik, M.A.; Chaffar, A.; Malik, S.A. Water purification by electrical discharges. Plasma Sources Sci. Technol. 2001, 10, 82-91. [CrossRef]

26. Zhou, R.W.; Zhou, R.S.; Wang, P.Y.; Luang, B.Y.; Zhang, X.H.; Fang, Z.; Xian, Y.B.; Lu, X.P.; Ostrikov, K.K.; Bazaka, K. Microplasma Bubbles: Reactive Vehicles for Biofilm Dispersal. ACS Appl. Mater. Interfaces 2019, 11, 20660-20669. [CrossRef]

27. Zhang, X.H.; Zhou, R.W.; Bazaka, K.; Liu, Y.; Zhou, R.S.; Chen, G.L.; Chen, Z.; Liu, Q.H.; Yang, S.Z.; Ostrikov, K. Quantification of plasma produced $\mathrm{OH}$ radical density for water sterilization. Plasma Process. Polym. 2018, 15, 1700241. [CrossRef]

28. Liu, Y.; Zhang, H.; Sun, J.; Liu, J.; Shen, X.; Zhan, J.; Zhang, A.; Ognier, S.; Cavadias, S.; Li, P. Degradation of aniline in aqueous solution using non-thermal plasma generated in microbubbles. Chem. Eng. J. 2018, 345, 679-687. [CrossRef]

29. Chen, B.; Zhu, C.; Fei, J.; Jiang, Y.; Yin, C.; Su, W.; He, X.; Li, Y.; Chen, Q.; Ren, Q.; et al. Reaction kinetics of phenols and p-nitrophenols in flowing aerated aqueous solutions generated by a discharge plasma jet. J. Hazard. Mater. 2019, 363, 55-63. [CrossRef]

30. Balba, H. Review of strobilurin fungicide chemicals. J Environ. Sci Health B 2007, 42, 441-451. [CrossRef]

31. Toor, H.L.; Marchello, J.M. Film-penetration model for mass and heat transfer. AIChE J. 1958, 4, 97-101. [CrossRef]

32. Wang, C.; Xu, Z.; Lai, C.; Sun, X. Beyond the standard two-film theory: Computational fluid dynamics simulations for carbon dioxide capture in a wetted wall column. Chem. Eng. Sci. 2018, 184, 103-110. [CrossRef]

33. Conrads, H.; Schmidt, M. Plasma generation and plasma sources. Plasma Sources Sci. Technol. 2000, 9, 441-454. [CrossRef]

34. Kukushkin, V.Y.; Pombeiro, A.J. Additions to metal-activated organonitriles. Chem. Rev. 2002, 102, 1771-1802. [CrossRef]

35. Radzicka, A.; Wolfenden, R. Rates of Uncatalyzed Peptide Bond Hydrolysis in Neutral Solution and the Transition State Affinities of Proteases. J. Am. Chem. Soc. 1996, 118, 6105-6109. [CrossRef]

36. Yoshino, Y.; Hayashi, Y.; Iwahama, T.; Sakaguchi, A.S.; Ishii, Y. Catalytic oxidation of alkylbenzenes with molecular oxygen under normal pressure and temperature by N-hydroxyphthalimide combined with Co(OAc)2. J. Org. Chem. 1997, 62, 6810-6813. [CrossRef] 
37. Yabuta, T.; Hayashi, M.; Matsubara, R. Photocatalytic Reductive C-O Bond Cleavage of Alkyl Aryl Ethers by Using Carbazole Catalysts with Cesium Carbonate. J. Org. Chem. 2021, 86, 2545-2555. [CrossRef] [PubMed]

38. Cornella, J.; Zarate, C.; Martin, R. Metal-catalyzed activation of ethers via C-O bond cleavage: A new strategy for molecular diversity. Chem. Soc. Rev. 2014, 43, 8081-8097. [CrossRef] [PubMed]

39. Smadja, W. Electrophilic addition to allenic derivatives: Selectivity, regio- and stereochemistry and mechanisms. Chem. Rev. 1983, 83, 263-320. [CrossRef] 